\title{
Respiratory medicine is not gender blind
}

\author{
Mina Gaga (1) ${ }^{1}$, Daiana Stolz², Joanna Chorostowska-Wynimko $\mathbb{1}^{3}$, Tobias Welte ${ }^{4}$ \\ and Anita Simonds ${ }^{5}$
}

\begin{abstract}
Affiliations: ${ }^{17}$ th Respiratory Medicine Dept, Athens Chest Hospital Sotiria, Athens, Greece. ${ }^{2}$ University Hospital Basel, Pulmonary Care Division, Basel, Switzerland. ${ }^{3}$ Institute of Tuberculosis and Lung Diseases, Warsaw, Genetics and Clinical Immunology, Warsaw, Poland. "University of Hannover, Pulmonary Medicine, Hannover, Germany. ${ }^{5}$ Royal Brompton and Harefield NHS Foundation Trust, NIHR Respiratory Biomedical Research Unit, London, UK.
\end{abstract}

Correspondence: Mina Gaga, Athens Chest Hospital Sotiria, 7th Respiratory Medicine Dept, 152 Mesogion Ave, Athens, 15452, Greece. E-mail: minagagadyahoo.com

@ERSpublications

Few women are still promoted to leadership positions and there seems to be an unconscious bias that must be changed http://bit.ly/2mET3t6

Cite this article as: Gaga M, Stolz D, Chorostowska-Wynimko J, et al. Respiratory medicine is not gender blind. Eur Respir J 2020; 55: 1901847 [https://doi.org/10.1183/13993003.01847-2019].

Marie Curie is a legendary figure: her research had huge impact on medicine, and she was the first woman to receive a Nobel Prize. In fact, she received two, one in Physics in 1903, and one in Chemistry in 1911, and so early in the history of Nobel Prizes (they were first awarded in 1901) a woman was a laureate. This was before women's suffrage in most parts of the world, and before any notion of gender equality, when few women had a chance to follow a career in science or medicine or get any education, and Marie Curie showed that it was possible. She was admired, respected and a role model for women in science. But still, more than 100 years later, few women have followed her footsteps: Between 1901 and 2018, there have been 902 Nobel laureates and of those, 52 were women [1]. In Medicine, 109 Nobel Prizes have been awarded, to 216 laureates. Of them only 12 were women. It seems that there is something holding women back from excelling. Importantly though, six of those women were laureates in the last 15 years. So hopefully the trend is changing.

What about women in respiratory medicine? Are women involved and do they get top marks and top jobs? Well some do, and names such as Sonia Buist, Ann Woolcock and Margaret Turner-Warwick spring to mind, but are these exceptions, and what progress has been made in the field? In this issue of the European Respiratory Journal, a group of female doctors look at the female representation in the leading/ expert positions in respiratory medicine [2]. To do this, they examined the participation and representation of women at respiratory congresses and in the leadership of three respiratory societies: the British Thoracic Society (BTS), Thoracic Society of Australia and New Zealand (TSANZ) and European Respiratory Society (ERS), the largest of all. They looked at the data of the 2017 annual congresses of these societies and what they report is that, although research data are submitted and presented by a slight majority of women, there are far fewer women as invited speakers and chairs. Moreover, RAVISKANTHAN et al. [2] report that the ERS is faring less well than either the BTS or TSANZ, with 23\% women speakers and $31 \%$ chairpersons versus $35 \%$ and $45 \%$ at BTS and $45 \%$ and $46 \%$ at TSANZ, respectively.

The data they present are in accordance with recent reports from Canada and the USA [3-5]. Almost half or more than half of medical students are women, yet, only $6-16 \%$ of deans or chairs of medicine are. The data have not changed much in the past 30 years, when a status report was published in the New England Journal of Medicine [6], stating that women comprised 34\% of medical students, $28 \%$ of residents, $19 \%$ of 
full-time medical school faculty members and only $9 \%$ of full professors. The report concluded that the numbers of women were increasing rapidly at the lower levels of medical education, but not at the upper levels, and the situation stays more or less the same. Still, male researchers receive more research funding than their female peers and when the funding programme focuses on the principal investigator rather than the proposed science, there is a significantly larger sex-related difference that disadvantages women [7].

Why is this, and what can international societies, and in particular our own society, the ERS, which is a large, global society, committed to helping the careers of our members, do about it?

Most of the older surveys and publications pointed to childbearing and family responsibilities as the reason for holding back the careers of women. However, the results of a survey of female doctors published 30 years ago [8] showed that $63 \%$ of the respondents had children and were working. Approximately half the respondents with children had their first child after completing medical training and they had been absent from work for a median of 6 weeks post-partum. $83 \%$ were back at work within 12 weeks while $72 \%$ had taken no time off before labour and delivery. Maternity and absence from work then do not seem to be a huge issue that held women back from getting promoted. In a recent Harvard business review, entitled "What's holding women in medicine back from leadership" [9], there are a number of reasons discussed. They include implicit gender and maternal bias, system-wide policies that disadvantage women, and sexual harassment. Of those reasons, implicit gender bias seems to be the most important and studies have shown that women are less likely to be hired or promoted because of their gender. Lack of role models, mentors and sponsors is a crucial issue. Mentors should help build resilience and self-belief. The importance of positive female imagery in medicine is increasingly recognised [10].

Interestingly, while recent experiments using hypothetical scenarios have showed scientists to favour women as junior faculty, randomised and real-world studies evaluating actual behaviours all favoured men $[11,12]$.These results point to the social desirability to achieve gender balance but unconscious bias preventing this ideal being put to action. The systemic bias unfairly favours men, particularly if leadership is included as a criterion. Women are condemned for being ambitious and often have to choose between being a respected leader or being liked. Women are also more modest about their achievements and less likely, on average, to boast about their future performance [13].

What can we do? In the ERS there is a rule about gender representation and participation as faculty in any event; this rule is that at least one third of the faculty should be women. However, this can be improved upon and we can proactively look for female candidate speakers and chairs. No all-male panels or "manels" should take place in any of the future ERS activities, following the pledge of the NIH director Francis S. Collins [14]. Men have a decisive word to say here by declining participation in activities that do not pay attention to inclusiveness.

We also try to bring new blood into the society, help the careers of our younger members and create tomorrow's leaders: in the ERS Early Careers Member Committee there are eight women and six men representing their peers in the assemblies and the ERS leadership: hopefully more women will be involved in the long term. And to help the members who are raising young families, the ERS offers childcare at its annual conference, thus allowing parents to attend sessions while their offspring enjoys high quality care at the congress venue.

Figure 1 shows data regarding the participation of women as speakers and chairs in the last four annual ERS congresses. Since 2017, there has been a growing participation of women in ERS congress activities. But we still have to work harder at senior level.

Some initiatives have been developed at institutional and national levels to promote the advancement of women to senior leadership positions. In an editorial published last year in Nature [15], the editors decided to counter unconscious bias, by getting senior staff and editors to ask themselves, "Who are the outstanding women for this task?", before commissioning an author or a referee. This strategy does not mean that a woman is necessarily invited to write that article; it means that women are considered at the outset and encouraged to contribute.

Similar strategies can be employed by ourselves or academic organisations, to ensure that women are invited and asked to come forward and that they are represented on search and award committees. There are of course local and national circumstances that the ERS cannot change but we can help build networks for research, link junior researchers with mentors and provide grants - and we do it. Moreover, a strategy on mentoring for women is being developed in the ERS and we hope it will be successful: already, there was a session devoted to women mentorship at the ERS international congress in Madrid. Nevertheless, it is important not only to help women reach senior leadership but also to ensure that, when they do get to senior posts, they are respected and encouraged within senior leadership positions. And that they are represented in all committees, that there are no committees run by men only. Here, we are not always 


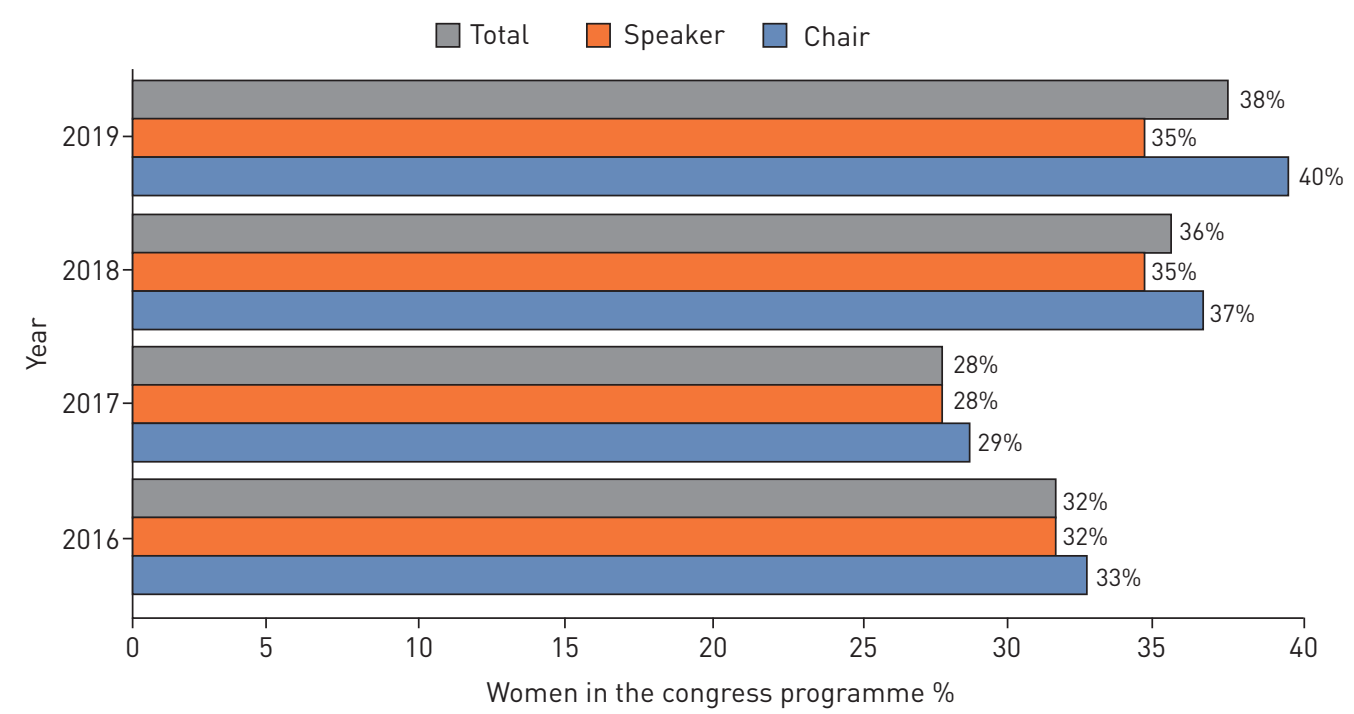

FIGURE 1 Facts and figures: faculty statistics and the participation of women as speakers and chairs in the past four annual European Respiratory Society congresses.

conscious or successful. For example, in the small ERS Core Management Group, women have so far been absent or in minority and we need to ensure female presence permanently. Moreover, although there are women in the Executive Committee and the Management Group, they are not the official representatives of the ERS in other organisations such as the Forum of International Respiratory Societies (FIRS), the Biomed Alliance or the European Organization for Research and Treatment of Cancer (EORTC). So, many decisions in the society do not involve women. Does it show unconscious bias? Probably. Is it important? Yes, it is. A study published in Science in 2010 [16] showed that in addition to the individual intelligence of a person, there is collective intelligence in the performance of human groups. The group intelligence is obviously dependent on the individual intelligence of the members but also on the way people interact. Groups behave better when their members have social sensitivity, when there are no dominating people and there is an equal distribution of conversation and tasks. And notably, a group's higher intelligence has significant positive association to the proportion of women, that is, more women, higher collective intelligence and better performance. This is due to the fact that women consistently score better on social sensitivity [16].

Therefore, discrimination against women is not only unfair and deleterious to women, it is deleterious to society. All our stakeholders, but in particular our patients, deserve the most capable healthcare professionals, educators, and scientists to be involved in their care, irrespective of gender. We cannot afford to keep missing $50 \%$ of our potential talent in academia and care because of barrier to women. We all need every bright mind, male and female, formulating and testing hypotheses, searching for explanations, pushing the boundaries of science and driving progress and enlightenment; we need the right questions to be posed, the best decisions to be taken, the decisive research to be granted, and the most appropriate solutions to be found. And we need compassion and team spirit. Any gender discrimination prevents the realisation of our vision: a better world. And in respiratory medicine and the ERS, our vision of a world free from suffering from respiratory disease. That is the setting we are aiming for.

It is now time to get metrics and then adapt our strategy to ensure that women are not only allowed to get promoted but truly expected to be in leadership positions. Metrics such as the ones described by the Association of American Medical Colleges in their report "The State of Women in Academic Medicine" [17, 18]: metrics on women entering the pipeline (medical school and residency positions), those in the pipeline (workforce numbers), and those leading the pipeline (from division leads to dean). For us, it would be metrics on early career members, on grant awardees, on junior and senior officers of the society. And the composition of the Executive Committee, the Management Group and the Core Management Group. But it is not only numbers, it is treating women in their rank with the same respect as that shown to men.

Conflict of interest: M. Gaga reports lecture fees and departmental grants from AZ, Novartis, GSK, Chiesi, Menarini, Roche, BMS, MSD and Galapagos, outside of the submitted work. D. Stolz reports lecture fees from AstraZeneca AG, Novartis AG, GSK AG, Roche AG, Zambon, Pfizer, Schwabe Pharma AG and Vifor AG, outside the submitted work. 
J. Chorostowska-Wynimko reports grants, personal fees and non-financial support from CSL Behring, Grifols, AstraZeneca, Boehringer Ingelheim and CelonPharma, personal fees and non-financial support from Pfizer, MSD, BMS and Abbvie, personal fees from GSK, Kamada, Novartis, Chiesi, Lekam, Takeda and Angelini. T. Welte has nothing to disclose. A. Simonds has nothing to disclose.

\section{References}

1 The Nobel Prize. Nobel Prize Facts. www.nobelprize.org/prizes/facts/nobel-prize-facts/

2 Raviskanthan M, Rees M, Douglass J, et al. Equal or not? Women hold less prestigious roles at respiratory medicine conferences than men. Eur Respir J 2020; 55: 9100701.

3 Lautenberger DM, Dandar VM, Raezer CL, et al. The State of Women in Academic Medicine: The Pipeline and Pathways to Leadership, 2013-2014. Washington, Association of American Medical Colleges, 2014. www.aamc. org/members/gwims/statistics/ Date last accessed: 22 April 2016.

4 Association of Faculties of Medicine of Canada. Canadian Medical Education Statistics. 2015. www.afmc.ca/ publications/canadian-medical-education-statistics-cmes. Date last accessed: 22 April 2016.

5 Canadian Association of Professors of Medicine. Membership. www.canapm.org/membership/ Date last accessed: 27 May 2016.

Bickel J. Women in medical education. A status report. N Engl J Med 1988; 319: 1579-1584.

Witteman HO. Gender bias in academia. Lancet 2019; 393: 743-744.

Levinson W, Tolle SW, Lewis C. Women in academic medicine. Combining career and family. N Engl J Med 1989; 321: 1511-1517.

9 Harvard Business Review. What's Holding Women in Medicine Back from Leadership. https://hbr.org/2018/06/ whats-holding-women-in-medicine-back-from-leadership Date last updated: 7 November 2018.

10 Boylan J, Dacre J, Gordon H. Addressing women's under-representation in medical leadership. Lancet 2019; 393 e14.

11 Reuben E, Sapienza P, Zingales L. How stereotypes impair women's careers in science. Proc Natl Acad Sci USA 2014; 111: 4403-4408.

12 Williams WM, Ceci SJ. National hiring experiments reveal 2:1 faculty preference for women on STEM tenure track. Proc Natl Acad Sci USA 2015; 112: 5360-5365.

13 Milkman KL, Akinola M, Chugh D. What happens before? A field experiment exploring how pay and representation differentially shape bias on the pathway into organizations. J Appl Psychol 2015; 100: 1678-1712.

14 Collins FS. National Institutes of Health. Time to End the Manel Tradition. www.nih.gov/about-nih/who-we-are/ nih-director/statements/time-end-manel-tradition Date last updated: 12 June 2019.

15 Nature's under-representation of women. Nature 2018; 558: 344.

16 Woolley AW, Chabris CF, Pentland A, et al. Evidence for a collective intelligence factor in the performance of human groups. Science 2010; 330: 686-688.

17 Jollif L, Leadley J, Coakley E, et al. Women in US Academic Medicine and Science: Statistics and Benchmarking Report. 2011-2012. Washington, Association of American Medical Colleges, 2012; www.aamc.org/download/ 415556/data/2011-2012wimsstatsreport.pdf Date last accessed: 22 April 2016.

18 Association of American Medical Colleges. The State of Women in Academic Medicine. www.aamc.org/members/ gwims/statistics/489870/stats16.html 